\title{
Percepção de agricultura sustentável no município de Maringá, Paraná, Brasil
}

\author{
Perception of sustainable agriculture in Maringá municipality, Paraná state, Brazil
}

Percepción de agricultura sostenible en el municipio de Maringá, Paraná, Brasil

\author{
Natália Christina da Silva Matos ${ }^{1}$ \\ Márcia Aparecida Andreazzi ${ }^{1}$ \\ Maria de Los Angeles Perez Lizama ${ }^{1}$ \\ Arthur Gualberto Bacelar da Cruz Urpia ${ }^{1}$
}

Recebido em 12/12/2018; revisado e aprovado em 22/07/2019; aceito em 06/08/2020

DOI: http://dx.doi.org/10.20435/inter.v22i3.2310

Resumo: Em decorrência do aumento populacional, é imprescindível a busca por formas de produção de alimentos em quantidade e que assegurem a qualidade e os cuidados ao meio ambiente. Nesta perspectiva, a produção agroecológica, incluindo a produção de orgânicos, surge como alternativa de sistemas sustentáveis de produção de alimentos. Contudo, muitos produtores e consumidores desconhecem estes modos de produção e seus benefícios relacionados, sobretudo, à saúde e ao meio ambiente. Desta forma, o objetivo desta pesquisa foi avaliar o grau de conhecimento de indivíduos participantes de um evento agrário e de uma feira do produtor, sobre os conceitos de produção e produtos convencionais, agroecológicos e orgânicos, a fim de revelar suas percepções sobre estes assuntos. Este estudo exploratório e transversal baseou-se na aplicação de questionário elaborado e validado. Os resultados mostraram que a maioria dos pesquisados é jovem ou adulto jovem, das classes sociais B e C, residente na zona urbana. Observaram-se diferenças quanto ao sexo e grau de escolaridade entre os grupos, sendo que, na feira do produtor a maioria dos entrevistados era do sexo feminino e com menor grau de escolaridade. Apesar dos resultados médios satisfatórios, foram evidenciadas lacunas do conhecimento ou percepções equivocadas sobre o assunto. Portanto, a fim de complementar e ajustar o conhecimento da comunidade sobre estes temas, considera-se imperativo que ações que fomentem a educação ambiental, ecológica e a alfabetização agroecológica sejam estimuladas, a fim de divulgar as características de um produto orgânico, suas formas de cultivo, incluindo os benefícios ambientais e suas restrições no cultivo, e, principalmente, propagar os benefícios à saúde proporcionados pelo consumo destes alimentos.

Palavras-chave: agroecologia; alfabetização agroecológica; feiras; produtos orgânicos.

Abstract: With the population increase, the search for solutions to produce food in quantity, ensuring quality and care for the environment is necessary. In this context, agroecological production, including organic farming, emerges as an alternative for sustainable food production systems. However, many producers and consumers are unaware of these forms of cultivation and their benefits related to health and the environment. In this way, the objective of this research was to evaluate the degree of knowledge of individuals participating in two agrarian events, on the concepts of production and conventional products, agroecological and organic, to reveal the perceptions about these subjects. This exploratory and transversal study was based on the application of an elaborated and validated questionnaire. The results showed that most of those surveyed are young or young adults, social classes B and C, living in the urban area. There were differences in gender and schooling among groups, and, in the producer's fair, the majority were female and with a lower level of schooling. Despite the satisfactory average results, gaps in the knowledge or misguided perceptions about the subject were emphasized. To complement and adjust the knowledge community on these subjects, it is considered imperative that actions that foster environmental education, ecological education, and agroecological literacy should be encouraged to designed to reveal the particular characteristics of an organic product, its cultivation methods including the environmental benefits and their restrictions, and, mainly, to propagate the health benefits of consuming these foods.

Keywords: agroecology; agroecological literacy; fairs; organic products.

Resumen: Como consecuencia del aumento de la población, es esencial la búsqueda por formas de formas de producción de alimentos en gran cantidad para asegurar la calidad y el cuidado del medio ambiente. En esta perspectiva, la producción agroecológica, incluyendo la producción orgánica, se presenta como alternativa de sistemas sostenibles de producción de alimentos. Sin embargo, muchos productores y consumidores desconocen estos modos de producción y sus beneficios, sobre todo, para la salud y el medio ambiente. Así,

\footnotetext{
${ }^{1}$ Centro Universitário de Maringá (UNICESUMAR), Maringá, Paraná, Brasil.
} 
el objetivo de esta investigación fue evaluar el grado de conocimiento de los individuos participantes de un evento agrario y de una feria del productor, en los conceptos de producción y productos convencionales, agroecológicos y orgánicos, con el fin de revelar sus percepciones sobre estos asuntos. Este estudio exploratorio y transversal se basó en la aplicación de cuestionario preparado y validado. Los resultados mostraron que la mayoría de los encuestados es joven o joven adulto, de las clases sociales B y C, residentes en el área urbana. Se observaron diferencias en cuanto a sexo y nivel de educación entre los grupos, siendo que en la feria del productor la mayoría de los encuestados era del sexo femenino y con menor nivel educacional. A pesar de los resultados promedios satisfactorios, se evidenciaron deficiencias de conocimiento o ideas erróneas sobre el tema. Por lo tanto, con el fin de complementar y ajustar los conocimientos de la comunidad acerca de estos temas, se considera vital que acciones que promuevan educación ambiental, ecológica y alfabetización agroecológica sean estimuladas, a fin de difundir las características de un producto orgánico, sus formas de cultivo, incluyendo los beneficios ambientales y sus restricciones sobre el cultivo, y, sobre todo, difundir los beneficios para la salud proporcionados por el consumo de estos alimentos.

Palabras clave: agroecología; alfabetización agroecológica; ferias; productos orgánicos.

\section{INTRODUÇÃO}

O modo de produção e consumo traz sérias ameaças ao planeta (ZULAUF, 2000), por isso o mundo precisa de soluções que busquem o aumento da produção de alimentos, sem comprometer ainda mais o meio ambiente (NASCIMENTO; MENDONÇA; CUNHA, 2012).

O aumento populacional e a necessidade em produzir alimentos para atender à demanda crescente vêm constituindo um grande entrave mundial, sendo necessária a busca por sistemas sustentáveis de produção de alimentos (HUNDLEY et al., 2013). Em função da sua importância e complexidade, este tema integra um dos Objetivos do Desenvolvimento Sustentável (ODS), o objetivo 2: "Acabar com a fome, alcançar a segurança alimentar e melhoria da nutrição e promover a agricultura sustentável" (UNESCO, 2015).

Atinentes à questão de segurança alimentar e cuidados com o meio ambiente, emerge como alternativa de sistemas sustentáveis de produção de alimentos a produção agroecológica, incluindo a produção de orgânicos.

A agricultura, que é a mais antiga atividade humana que relaciona a natureza com a sociedade, vem se desenvolvendo de forma positiva mundialmente, satisfazendo a crescente demanda por alimentos desde a metade do século XX (JACOB, 2016). Contudo, esta crescente produção, tanto para alimentação humana quanto animal, constitui-se em uma das atividades que mais utilizam recursos naturais, como água, energia, minerais e solo; por isso, é a principal causa do desmatamento e da perda de biodiversidade no planeta e a segunda maior emissora de gases do efeito estufa (SORRENTINO et al., 2015). Neste panorama, o Brasil apresenta um papel singular, pois, de um lado, é um dos principais produtores e exportadores de soja, carne bovina e açúcar, sendo um país estratégico e promissor para a produção de alimentos para o mundo, e, por outro lado, declina em função das questões ambientais negativas relacionadas aos sistemas de produção.

No tocante às técnicas de produção de alimentos, elenca-se o cultivo convencional, envolvendo os hidropônicos e transgênicos, e em sistema agroecológico, incluindo a produção de orgânicos. O sistema de produção convencional implica na utilização intensiva de insumos e tecnologias agrícolas, buscando a produtividade em larga escala; contudo, traz como desvantagem a utilização extensiva de agrotóxicos (SANTOS, 2013). Portanto, verifica-se que as formas convencionais nem sempre se associam positivamente à conservação do meio ambiente e à qualidade nutricional dos alimentos. 
Jacob (2016) afirma que a agricultura convencional não é sustentável, porque todas as práticas comprometem as gerações futuras, uma vez que geram impactos ambientais, como desperdício de água, degradação do solo, poluição do ambiente, perda de biomas e desperdício de alimentos e desigualdade social no meio rural. Desta forma, fica claro que a agricultura do futuro deve ser altamente produtiva, a fim de suprir a demanda mundial, entretanto não pode causar prejuízos ao meio ambiente e à saúde das pessoas, sendo necessária uma nova abordagem, pautada na agroecologia e em produtos orgânicos. Isto significa que os processos produtivos atuais precisam ser revistos, de forma que não se busque apenas ampliação da produtividade, mas também uma produção saudável de alimentos saudáveis tanto para os consumidores quanto para o meio ambiente.

Os produtores orgânicos geralmente usam sementes obtidas de práticas orgânicas e fertilizantes derivados da natureza, como os dejetos de animais, que são ricos em minerais (ALMEIDA et al., 2008), demonstrando que esta forma de produção tem como base os princípios da produção agroecológica, como o uso saudável e responsável da água, do solo, do ar e dos demais recursos naturais (SANTOS, 2013).

A agroecologia, na qual a produção orgânica está inserida, integra os princípios agronômicos, ecológicos, culturais e socioeconômicos (ALTIERI, 2004), incentiva as práticas de cultivo favoráveis ao meio ambiente e a necessidade de diálogo entre produtores e consumidores, com o propósito de oferecer alimentos aos humanos e ao ambiente (BRITO; MELLO, 2016).

Jacob (2016) afirma que a agroecologia busca simplificar os processos agrícolas e é uma resposta às consequências da crise ecológica. Contudo, na busca por sistemas de produção mais sustentáveis, como agroecologia e produção de orgânicos, deparamo-nos com a fragilidade de conhecimento das pessoas sobre estes sistemas (PIMENTA et al., 2009; MORAES et al., 2015; PANTALEÃO et al., 2015; PEREIRA et al., 2015; VACCARI; COHEN; ROCHA, 2016). Diante do exposto e ponderando sobre a importância do diálogo e da articulação com toda sociedade, a fim de incentivar, fortalecer e ampliar os sistemas de produção orgânicos e de base agroecológica, recomenda-se o emprego de ações no âmbito da educação ambiental, sobretudo da alfabetização agroecológica, a fim de conscientizar a comunidade e divulgar os conceitos sobre estas formas de produção.

A educação ambiental envolve valores, teorias e práticas que almejam a manutenção da vida e a construção de um mundo melhor para humanos e demais seres que habitam o planeta, assim como busca o enfrentamento da degradação socioambiental por meios dialógicos e participativos. Dada a sua importância, foi criada, em 27 de abril de 1999, a Lei n. 9.795, que dispôs sobre a Educação Ambiental e instituiu a Política Nacional de Educação Ambiental (PNEA), afirmando que a educação ambiental contempla valores, teorias e práticas que buscam a manutenção da vida e a construção de um mundo melhor, objetivando enfrentar a degradação socioambiental por meios dialógicos e participativos (BRASIL, 1999).

O uso dos preceitos da educação ambiental para promoção da educação e alfabetização agroecológica e de produtos orgânicos é complementar e busca a ressignificação na relação entre as pessoas e delas com o meio ambiente, objetivando os cuidados com a terra, a biodiversidade, a produção de alimentos saudáveis e a promoção de modos de vida mais sustentáveis no campo e na cidade (LEME; LUCAS; SORRENTINO, 2017). Com efeito, Altieri (2004) sugeriu que, diante da importância da agroecologia, para a formação do cidadão do século XXI, é preciso incorporar no currículo educacional discussões sobre temas e métodos agroecológicos, a fim de sensibilizar a população sobre este assunto. Com base no exposto, o objetivo desta pesquisa foi avaliar o grau 
de conhecimento de indivíduos participantes de um evento agrário e de uma feira do produtor, sobre os conceitos de produção e produtos agroecológicos e orgânicos, a fim de revelar suas percepções sobre estes assuntos.

\section{METODOLOGIA}

Este estudo exploratório e transversal se baseou na aplicação de questionário elaborado, validado e aplicado em uma amostra definida, de acordo com a metodologia descrita a seguir.

\subsection{Caracterização e validação do instrumento de percepção}

O instrumento de coleta de dados adotado foi um questionário desenvolvido pelos pesquisadores, baseado em outras pesquisas com objetivos semelhantes aos deste estudo (PIMENTA et al., 2009; VERONA et al., 2009; PEREIRA et al., 2015) e no Plano Nacional de Agroecologia e Produção Orgânica (PLANAPO), que é uma política pública do Governo Federal criada para ampliar e efetivar ações para orientar o desenvolvimento rural sustentável (BRASIL, 2013; 2016). Foi validado por diferentes docentes do programa de pós-graduação sede da pesquisa. A fim de identificar ambiguidades e falta de clareza, 10 voluntários avaliaram o questionário no que diz respeito à aparência e ao conteúdo.

A ordem cronológica das etapas de elaboração, a determinação da confiabilidade e a validação do questionário foram baseadas em Reichenheim e Moraes (2007) e Aaker et al. (2015): definição do construto, formulação dos itens, adequação da semântica dos itens, escalonamento das respostas, realização do pré-teste e consolidação do instrumento, que consiste num procedimento para constatar o cumprimento das três etapas - dimensionalidade, confiabilidade e validade para avaliar a confiabilidade.

Para a análise de confiabilidade dos dados obtidos pelo questionário, foi utilizado o Coeficiente Alfa de Cronbach ( $\alpha$ ), que é uma medida de confiabilidade comumente utilizada como uma estimativa de correlação entre duas amostras aleatórias de itens de um determinado universo (CRONBACH, 1951; HORA; MONTEIRO; ARICA, 2010; MATTHIENSEN, 2011). Os valores do coeficiente Alfa de Cronbach variam de 0,0 a 1,0; quanto mais próximo de 1,0, maior confiabilidade entre os indicadores (LOESCHI; HOELTGEBAUM, 2012; URPIA; MASSUDA; MACHADO, 2017).

O questionário apresentou 15 questões, e o respondente indicou apenas uma (resposta única) e abordou os seguintes aspectos: 1) características sociodemográficas e econômica dos entrevistados (7 questões): o município onde reside, se mora em zona rural ou urbana, sexo, idade, grau de escolaridade e renda mensal média; 2) questão específica, aberta, sobre o conhecimento e definição dos termos: alimento orgânico, agroecológico e convencional (1 questão); e 3) questões cujas categorias de respostas foram "sim" e "não" (7 questões) que versaram sobre comparação entre produto convencional e orgânico nos quesitos produto (se saudável ou não, composição nutritiva, aparência, cor, tamanho, sabor e preço) e relacionadas ao cultivo (impacto ambiental, uso de agroquímicos, mão de obra no cultivo, restrição no cultivo, consumo de água, consumo de energia), sendo que as opções de resposta eram: equivalente ao convencional, menos que o convencional ou mais que o convencional. Também, abordou-se a identificação dos fatores que podem ser considerados na produção de orgânicos, tais como solo, planta, condições climáticas, ecologia, agropecuária, economia e sociedade; se no cultivo de alimentos orgânicos é permitido o uso de dejetos animais criados em sistema convencional; se existe relação entre produção orgânica 
e sustentabilidade para a agricultura; se produtos agroecológicos e orgânicos são sinônimos; se produtos denominados caipiras podem ser considerados orgânicos; e se a produção orgânica prejudica a saúde, o meio ambiente ou a saúde e o meio ambiente.

\subsection{Aplicação do instrumento}

Local e época: a pesquisa foi conduzida em dois eventos ocorrentes no município de Maringá (longitude: 51ㅇ57'W e altitude: 596 m), estado do Paraná, no segundo semestre de 2017.

Os eventos escolhidos foram o evento agrário Dia de Campo da UNICESUMAR e a Feira do Produtor de Maringá. O Dia de Campo da UNICESUMAR é um evento que envolve um público constituído por produtores rurais, população urbana, estudantes de diferentes áreas do conhecimento e profissionais, totalizando aproximadamente 4.000 participantes, provenientes de mais de 40 municípios da região de Maringá, PR. Este evento é calendarizado e acontece uma vez em fevereiro e outra em agosto, sendo que os dados foram coletados no evento de agosto, em um único dia, pela manhã, sendo esse o horário com maior número de visitantes. A Feira do Produtor de Maringá é uma feira que conta com 125 barracas de venda no varejo, é calendarizada e acontece três vezes na semana, das $17 \mathrm{~h}$ às $21 \mathrm{~h}$. A coleta de dados na feira aconteceu uma vez por semana, durante um mês. Desta forma, a amostragem empregada foi por conveniência, que é um tipo de amostragem probabilística que consiste em selecionar uma amostra da população que seja acessível (PRODANOV; FREITAS, 2013).

Amostra: no evento agrário - dia de campo, participaram da pesquisa 170 indivíduos de ambos os sexos, com idade entre 18 e 60 anos. Como técnica de amostragem, foi empregada uma amostragem probabilística aleatória simples, uma vez que foi calculado o tamanho da amostra $^{2}$ para uma população de 4.000 participantes, com um erro amostral de 5\% e um nível de confiança de $90 \%$, o que deu um resultado de 167 participantes; portanto, um número maior do que o mínimo necessário para a obtenção deste tipo de amostragem. Além disso, os 170 participantes da pesquisa foram selecionados aleatoriamente. Faz-se importante destacar que a aplicação de uma técnica de amostragem probabilística aleatória simples é relevante, pois os resultados provenientes deste tipo de amostra podem ser generalizados estatisticamente para a população da pesquisa. Ou seja, este tipo de amostragem nos dará resultados que são estatisticamente significativos (BRITO, 2016).

Já para a feira do produtor, como era inacessivel o tamanho da população que participou deste evento, isto por se tratar de uma feira de rua e, portanto, aberta ao público, não foi possível empregar o cálculo para se obter uma amostragem probabilística (BRITO, 2016). Com isto, foi utilizada uma técnica de amostragem não probabilística por conveniência, em que participaram da pesquisa as pessoas acessíveis (BRITO, 2016). Ou seja, a amostra foi constituída por pessoas que aceitaram o convite de participar da pesquisa, o que totalizou 114 indivíduos, de ambos os sexos e com idade entre 18 e 60 anos.

Durante os dois eventos, os sujeitos foram abordados ao acaso e, após serem esclarecidos os objetivos da pesquisa, destacando a confidencialidade em relação aos dados e garantindo a liberdade do participante de optar por responder ou não, eles foram convidados a assinarem o Termo de Consentimento Livre e Esclarecido. Enfatiza-se que o tema não foi previamente discutido

\footnotetext{
2 Para o cálculo do tamanho da amostra, foi utilizada uma calculadora amostral on-line, acessada em: https://comentto. com/calculadora-amostral/
} 
com os participantes. O tempo médio de coleta de dados foi de, aproximadamente, 10 minutos. O projeto foi encaminhado e aprovado pelo Comitê de Ética em Pesquisa com Seres Humanos.

Análise dos dados: para a análise dos resultados coletados pelo questionário, foi aplicada uma abordagem quantitativa. Os resultados foram apurados por meio de técnicas de estatística descritiva, tais como análise de distribuição de frequência absoluta e relativa dos dados. Os dados foram tabulados e analisados empregando o software Statistical Analysis System (SAS ${ }^{\circledR}$ v.9.3, Cary, North Carolina), que analisa frequências e proporções.

\section{APRESENTAÇÃO DOS DADOS E DISCUSSÃO DOS RESULTADOS}

\subsection{Análise da consistência dos dados do instrumento}

Para análise da confiabilidade e consistência dos dados provenientes da pesquisa, foi realizada a tabulação dos dados e o cálculo do alfa de Cronbach, por meio de programa de planilha eletrônica. Para esta análise, o questionário foi dividido em duas seções - uma referente à questão comparativa entre produto orgânico e convencional, nos quesitos produto e cultivo, em que cada item da tabela foi transformado em itens de uma planilha, gerando 13 itens para um total de $170+$ $114=284$ respondentes. O valor do alfa de Cronbach sobre os 13 itens que representam o nível de implantação de todas as práticas contidas no instrumento de diagnóstico foi de 0,7528 . Este valor representa um nível de consistência "boa" segundo a escala de Loeschi e Hoeltgebaum (2012).

Na análise da segunda seção, que contemplou as questões sobre o que deve ser considerado e a importância fundamental dos sistemas de produção de orgânicos, cada item da tabela foi transformado em itens de uma planilha, gerando 14 itens para um total de $170+114=284$ respondentes, e o valor de alfa do Cronbach mostrou um nível de alcance de 0,8121. Este valor representa um nível de consistência "muito boa", segundo a mesma escala utilizada como parâmetro para análise do coeficiente Alfa de Cronbach para o nível de implantação (LOESCHI; HOELTGEBAUM, 2012).

Estes dados mostram que as respostas decorrentes da aplicação do instrumento de diagnóstico aplicado têm confiabilidade e, diante da validade da escala e da sua confiabilidade, observa-se que a pesquisa realizada tem robustez.

\subsection{Resultados e discussão dos dados do estudo}

Mesmo sendo eventos distintos, que ocorreram em dias e horários diferentes, os dados sobre a caracterização sociodemográfica (Tabela 1) mostraram que, tanto no evento agrário quanto na feira do produtor, a maioria dos entrevistados reside na zona urbana. No evento agrário, houve paridade quanto ao sexo dos participantes; contudo, na feira do produtor, a maioria era do sexo feminino (76,31\%). Mais de $50 \%$ dos entrevistados eram jovens e adultos jovens, com idade entre 21 e 40 anos. Com relação ao grau de escolaridade, nos dois grupos entrevistados, observouse maior frequência de indivíduos com ensino superior; contudo, no evento agrário - dia de campo, esta frequência foi maior (77,65\%) do que no grupo da feira (47,36\%). Grande parte dos entrevistados tem renda familiar mensal entre 3 e 8 salários, sendo classificados em classe B e C.

Em pesquisa similar, também no município de Maringá, PR, Pimenta et al. (2009) constataram como perfil pessoal dos consumidores que o consumo é maior nas categorias acima de 30 anos de idade, com renda mensal acima de 4 salários mínimos e escolaridade avançada. 
Pantaleão et al. (2015), em pesquisa semelhante conduzida com o objetivo de identificar o perfil do consumidor de produtos orgânicos em uma feira em Cuiabá, MT, observaram também, com relação ao gênero, uma predominância da presença feminina e creditaram este resultado ao fato de que, geralmente, as mulheres são as responsáveis pela compra dos alimentos para a família. Os valores reportados pelos pesquisadores citados, referentes à faixa etária e renda mensal dos frequentadores da feira, foram também semelhantes aos encontrados nesta pesquisa, bem como o nível de escolaridade, sendo $50 \%$ dos indivíduos com ensino superior completo.

Em uma pesquisa realizada com frequentadores do evento agrário Dia de Campo da UNICESUMAR, em 2016, sobre o grau de conhecimento sobre o caramujo-gigante-africano (Achatina fulica), Andreazzi et al. (2017), encontraram também um perfil sociodemográfico dos entrevistados semelhante ao obtido neste estudo. Neste caso, considera-se esta igualdade ao fato de ser, mesmo que em anos diferentes, o mesmo evento.

Com relação à frequência de consumo (Tabela 2), verificou-se um baixo consumo semanal médio de produtos orgânicos (50\%), visto que, aproximadamente, metade dos entrevistados apontou não consumir ou consumir, no máximo, 2 vezes por semana estes produtos. Ao contrário, em pesquisa equivalente também conduzida no município de Maringá, PR, no ano de 2009, $64,5 \%$ dos entrevistados alegaram consumir alimentos orgânicos às vezes e frequentemente (PIMENTA et al., 2009).

Tabela 1 - Frequência das características sóciodemográficas dos indivíduos entrevistados no evento agrário $(n=170)$ e na feira do produtor $(n=114)$, no município de Maringá, PR

\begin{tabular}{|c|c|c|c|}
\hline Amostragem (indivíduo) & $\begin{array}{c}\text { Evento agrário } \\
\mathrm{n}(\%)\end{array}$ & $\begin{array}{c}\text { Feira do produtor } \\
\mathrm{n}(\%)\end{array}$ & $\begin{array}{l}\text { Média } \\
\text { n (\%) }\end{array}$ \\
\hline \multicolumn{4}{|l|}{ Variável } \\
\hline \multicolumn{4}{|l|}{ Residência } \\
\hline Zona urbana & $159(93,53)$ & $98(85,96)$ & $128,5(89,74)$ \\
\hline Zona rural & $11(6,47)$ & $16(14,04)$ & $13,5(10,25)$ \\
\hline \multicolumn{4}{|l|}{ Sexo } \\
\hline Feminino & $72(42,35)$ & $87(76,31)$ & $79,5(59,33)$ \\
\hline Masculino & $98(57,65)$ & $27(23,69)$ & $62,5(40,67)$ \\
\hline \multicolumn{4}{|l|}{ Idade } \\
\hline De 18 a 20 anos & $34(20)$ & $12(10,53)$ & $23(15,26)$ \\
\hline De 21 a 30 anos & $86(50,5)$ & $38(33,33)$ & $62(41,91)$ \\
\hline De 31 a 40 anos & $12(7,06)$ & $26(22,81)$ & $19(14,93)$ \\
\hline De 41 a 50 anos & $21(12,35)$ & $13(11,4)$ & $17(11,87)$ \\
\hline De 51 a 60 anos & $9(5,29)$ & $20(17,54)$ & $14,5(11,41)$ \\
\hline Acima de 60 & $8(4,71)$ & $5(4,39)$ & $6,5(4,55)$ \\
\hline \multicolumn{4}{|l|}{ Escolaridade } \\
\hline Ensino Fundamental & $1(0,59)$ & $19(16,66)$ & $10(8,62)$ \\
\hline Ensino Médio & $37(21,76)$ & $41(35,98)$ & $39(28,87)$ \\
\hline Ensino Superior & $132(77,65)$ & $54(47,36)$ & $93(62,50)$ \\
\hline \multicolumn{4}{|l|}{ Renda familiar } \\
\hline 1 a 2 salários & $25(15,15)$ & $36(31,58)$ & $30,5(23,36)$ \\
\hline 3 a 5 salários & $61(36,97)$ & $36(31,58)$ & $48,5(34,27)$ \\
\hline 6 a 8 salários & $45(27,27)$ & $30(26,32)$ & $37,5(26,79)$ \\
\hline Acima de 9 salários & $39(22,94)$ & $12(10,53)$ & $25,5(16,74)$ \\
\hline
\end{tabular}

Fonte: Os próprios autores. 
Tabela 2 - Frequência de consumo de alimentos orgânicos dos indivíduos entrevistados no evento agrário $(n=170)$ e na feira do produtor $(n=114)$, no município de Maringá, PR

\begin{tabular}{lccc}
$\begin{array}{c}\text { Frequência que consome } \\
\text { alimento orgânico }\end{array}$ & $\begin{array}{c}\text { Dia de campo }(\mathbf{n}=\mathbf{1 7 0}) \\
\mathbf{\%}(\mathbf{n})\end{array}$ & $\begin{array}{c}\text { Feira do produtor }(\mathbf{n}=\mathbf{1 1 4}) \\
\mathbf{\%}(\mathbf{n})\end{array}$ & $\begin{array}{c}\text { Média } \\
\mathbf{\%}\end{array}$ \\
\hline Nunca a 2 vezes & $57,05(97)$ & $42,95(49)$ & 50,03 \\
3 a 4 vezes & $23,53(40)$ & $21,93(25)$ & 22,73 \\
5 vezes a diariamente & $19,41(33)$ & $35,08(40)$ & 27,24 \\
\hline
\end{tabular}

Fonte: Os próprios autores.

Verona et al. (2009) avaliaram o perfil do consumidor da feira de produtos orgânicos na cidade de Chapecó, SC, e perceberam que muitas pessoas não têm o hábito de consumir produtos orgânicos por não terem ciência dos benefícios que estes produtos trazem para a saúde e, também, em função do comodismo na realização de suas compras. Contudo, este fato não foi evidenciado neste estudo, já que mais de $80 \%$ dos entrevistados nos dois eventos (Tabela 5) demonstraram compreender que uma questão fundamental a ser considerada na produção orgânica é o fato de não prejudicar a saúde e o meio ambiente. Logo, pode-se inferir que este baixo consumo possa estar relacionado à questão de comodismo no momento da compra e ao fator custo, visto que mais da metade (Tabela 4) reportou que o valor do produto orgânico é superior ao produto cultivado de forma convencional, apesar da favorável renda familiar, permeando entre as classes B e C.

De acordo com os resultados sobre a frequência de consumo, verifica-se a necessidade de ações que fomentem a Política Nacional de Produção e Consumo Sustentáveis (PNPCS) e seu Plano de Ação para Produção e Consumo Sustentáveis (PPCS), bem como a Política de Educação para o Consumo Sustentável (PECS).

O PPCS foi lançado em 23 de novembro de 2011 (BRASIL, 2011b) e se constituiu num documento norteador das ações de governo, do setor produtivo e da sociedade para conduzir o Brasil a padrões mais sustentáveis. Este plano articulou as principais políticas ambientais e de desenvolvimento do país, contribuindo para o alcance de suas metas por meio do estímulo de práticas produtivas sustentáveis e da adesão do consumidor. Em seu primeiro período, de 2011 a 2014, o PPCS teve seus esforços focados em seis áreas, entre elas, a Educação para o Consumo Sustentável (BRASIL, 2011b). Os primeiros ensaios legislativos da Política Nacional de Produção e Consumo Sustentáveis (PNPCS) nasceram no Brasil como frutos dos princípios basilares da proteção do meio ambiente e da ordem econômica, existentes na Constituição Federal. Segundo Feitosa (2016), progressos significativos são esperados no atendimento desta urgente demanda econômica, ambiental e social, fato evidenciado neste estudo.

A Lei n. 13.186, de 11 de novembro de 2015, instituiu a Política de Educação para o Consumo Sustentável (PECS), com o objetivo de estimular a adoção de práticas de consumo e de técnicas de produção ecologicamente sustentáveis. Entre seus objetivos, destaca-se o incentivo às mudanças de atitude dos consumidores na escolha de produtos que sejam produzidos com base em processos ecologicamente sustentáveis. Esta lei incumbe também ao poder público, em âmbito federal, estadual e municipal, a promoção de campanhas em prol do consumo sustentável, em espaço nobre dos meios de +comunicação de massa, e a capacitação dos profissionais da área de educação para inclusão do consumo sustentável nos programas de educação ambiental do ensino médio e fundamental (BRASIL, 2015). 
Com relação ao questionamento sobre as variáveis que devem ser consideradas no cultivo orgânico (Tabela 3), metade dos entrevistados, em ambos os grupos, afirmou que a planta, o solo, as condições climáticas, a ecologia, a agropecuária, a economia e a sociedade devem ser considerados no sistema de produção orgânica. Entretanto, no evento agrário - dia de campo, a porcentagem foi bem maior, e este fato talvez seja decorrente do nível de instrução dos participantes entrevistados, visto que $77,65 \%$ dos entrevistados deste grupo têm ensino superior.

Tabela 3 - Frequência de indivíduos que responderam "sim" em relação aos pontos a serem considerados no sistema de produção orgânica

\begin{tabular}{lccc}
\multicolumn{1}{c}{ Variável } & $\begin{array}{c}\text { Dia de campo } \\
\mathbf{\%}(\mathbf{n})\end{array}$ & $\begin{array}{c}\text { Feira do produtor } \\
\mathbf{\%}(\mathbf{n})\end{array}$ & $\begin{array}{c}\text { Média } \\
\%\end{array}$ \\
\hline Planta & $98,82(168)$ & $58,41(66)$ & 78,61 \\
Solo & $96,47(164)$ & $67,86(76)$ & 82,16 \\
Condições climáticas & $88,24(150)$ & $68,14(77)$ & 78,19 \\
Ecologia & $97,65(166)$ & $69,64(78)$ & 78,61 \\
Agropecuária & $82,35(140)$ & $71,68(81)$ & 83,64 \\
Economia & $88,24(150)$ & $62,83(71)$ & 75,53 \\
Sociedade & $91,18(155)$ & $59,29(67)$ & 75,23 \\
\hline
\end{tabular}

Fonte: Os próprios autores.

Pantaleão et al. (2015) observaram que 63\%, de um total de 46 consumidores entrevistados em uma feira de orgânicos que acontece no campus de uma universidade de Mato Grosso, têm informação suficiente sobre produtos agroecológicos e orgânicos. Eles atribuíram o valor encontrado ao nível de escolaridade dos entrevistados, já que a maioria estava cursando ou já havia concluído o ensino superior.

Estes dados (Tabela 3) são promissores e demonstram que o conhecimento da população brasileira sobre esta temática apresenta sincronismo com o relatório The World Organic Agriculture, o qual mostra que o Brasil vem conquistando uma posição privilegiada no mercado de produção de alimentos orgânicos e encontra-se entre os maiores produtores mundiais (WILLER; KILCHER, 2010).

O levantamento sobre a percepção das características relacionadas ao produto e ao modo cultivo de produto orgânico em comparação à agricultura convencional mostrou uma grande heterogeneidade nas frequências entre os grupos e entre os quesitos avaliados (Tabela 4). 
Tabela 4 - Frequência sobre a comparação entre produto e cultivo convencional e orgânico

\begin{tabular}{|c|c|c|c|c|c|c|}
\hline & \multicolumn{2}{|c|}{$\begin{array}{c}\text { Equivalente ao } \\
\text { convencional }\end{array}$} & \multicolumn{2}{|c|}{$\begin{array}{l}\text { Menos que o } \\
\text { convencional }\end{array}$} & \multicolumn{2}{|c|}{$\begin{array}{l}\text { Mais que o } \\
\text { convencional }\end{array}$} \\
\hline & $\begin{array}{c}\text { Evento } \\
\text { agrário } \\
\%(\mathrm{n})\end{array}$ & $\begin{array}{c}\text { Feira do } \\
\text { produtor } \\
\%(n)\end{array}$ & $\begin{array}{c}\text { Evento } \\
\text { agrário } \\
\%(\mathrm{n})\end{array}$ & $\begin{array}{c}\text { Feira do } \\
\text { produtor } \\
\%(n)\end{array}$ & $\begin{array}{c}\text { Evento } \\
\text { agrário } \\
\%(\mathrm{n})\end{array}$ & $\begin{array}{c}\text { Feira do } \\
\text { produtor } \\
\%(n)\end{array}$ \\
\hline \multicolumn{7}{|l|}{ Produto } \\
\hline Saudável & $11,76(20)$ & $21,93(25)$ & $6,47(11)$ & $7,02(8)$ & $81,76(139)$ & $71,05(81)$ \\
\hline Composição nutritiva & $40,00(68)$ & $28,95(33)$ & $16,47(28)$ & $16,67(19)$ & $43,53(74)$ & $54,39(62)$ \\
\hline Aparência & $27,06(46)$ & $28,07(32)$ & $43,53(74)$ & $38,6(44)$ & $29,41(50)$ & $33,33(38)$ \\
\hline Cor & $38,24(65)$ & $29,82(34)$ & $34,12(58)$ & $39,47(45)$ & $27,65(47)$ & $30,71(35)$ \\
\hline Tamanho & $27,06(46)$ & $26,32(30)$ & $54,71(93)$ & $33,33(38)$ & $18,24(31)$ & $40,35(46)$ \\
\hline Sabor & $26,47(45)$ & $26,32(30)$ & $8,24(14)$ & $33,33(38)$ & $65,29(111)$ & $40,35(46)$ \\
\hline Preço & $9,41(16)$ & $32,46(37)$ & $7,06(12)$ & $33,33(38)$ & $83,53(142)$ & $34,21(39)$ \\
\hline \multicolumn{7}{|l|}{ Cultivo } \\
\hline Impacto ambiental & $6,47(11)$ & $31,86(36)$ & $82,94(141)$ & $46,9(53)$ & $10,59(18)$ & $21,24(24)$ \\
\hline Uso de produtos químicos & $4,12(7)$ & $31,57(36)$ & $88,82(151)$ & $50,87(58)$ & $7,06(12)$ & $16,81(20)$ \\
\hline Mão de obra no cultivo & $11,18(19)$ & $34,21(39)$ & $11,76(20)$ & $49,12(56)$ & $77,06(131)$ & $16,67(19)$ \\
\hline Restrição no cultivo & $20,59(35)$ & $37,73(43)$ & $26,47(45)$ & $40,35(46)$ & $52,94(90)$ & $21,92(25)$ \\
\hline Consumo de água & 46,47 (79) & $40,36(46)$ & $14,71(25)$ & $37,71(43)$ & $38,82(66)$ & $21,93(25)$ \\
\hline Consumo de energia & $45,29(77)$ & $40,36(46)$ & $30,59(52)$ & $33,33(38)$ & $24,12(41)$ & $26,31(30)$ \\
\hline
\end{tabular}

Fonte: Os próprios autores.

A percepção de que os produtos orgânicos são mais saudáveis e têm melhor composição nutritiva foi apontada por ambos os grupos estudados. Sobre a aparência e cor do produto orgânico em comparação ao convencional, verificou-se uma percepção igualitária entre os grupos e entre os quesitos. Contudo, sobre o tamanho, 54,71\% dos participantes do evento agrário - dia de campo afirmaram que o produto orgânico é menor do que o convencional; por outro lado, 40,35\% dos frequentadores da feira apontaram que o produto orgânico apresenta maior tamanho. Acerca do sabor do produto orgânico, 65,29\% e 40,35\% dos frequentadores do evento agrário - dia de campo e da feira, respectivamente, alegaram que o sabor é melhor do que o alimento convencional.

Pereira et al. (2015) avaliaram também a percepção de frequentadores de feiras agroecológicas no Rio Grande do Sul sobre aparência, tamanho, cor e sabor. Constataram que $59,82 \%$ dos consumidores relataram que os produtos orgânicos têm melhor aparência e 86,51\% afirmaram serem mais saborosos que o convencional. O valor referente ao sabor, citado por Pereira et al. (2015), é semelhante ao citado por Lima Filho (2012), que afirmou que 80,31\% dos entrevistados em sua pesquisa consideraram também o produto orgânico mais saboroso e com melhor aparência; todavia, estes valores são superiores ao valor médio encontrado neste diagnóstico, que foi de 51,32\%. Pondera-se que, para Schmith e Zuliani (2018), o produto orgânico não apresenta diferenças evidentes referentes ao produto convencional, seja pelo sabor, seja pela cor, ou pela forma.

No tocante ao preço do produto orgânico, 83,53\% dos entrevistados do evento agrário - dia de campo apontaram que o valor é superior ao produto convencional; por outro lado, os dados obtidos dos entrevistados na feira do produtor permitem observar uma distribuição equânime entre as percepções nas três categorias: mais, menos ou equivalente. Este resultado demonstra 
que, apesar de serem frequentadores de um local de comércio de produtos convencionais e orgânicos, existe uma compreensão equivocada deste grupo sobre os custos praticados para estes produtos.

Atinente ao preço, Pereira et al. (2015) constataram que metade dos entrevistados relatou que os produtos orgânicos são mais caros que os convencionais. Contudo, em pesquisa realizada na cidade de Maringá, PR, a maioria dos consumidores afirmou estar disposta a pagar um sobrepreço nos produtos orgânicos, entretanto, menos da metade destes consumidores estavam dispostos a pagar somente até $10 \%$ a mais em relação ao preço dos produtos convencionais. Sendo assim, observa-se que a variável preço se constitui em um fator relevante na caracterização e compra do produto orgânico no município em questão. Destaca-se que em meio a um cenário de crise econômica no país, o preço dos alimentos impacta diretamente no orçamento familiar (FONSECA; BITTENCOURT; PICININ, 2017), mas, independentemente do preço, o consumo de alimentos orgânicos vem crescendo no mundo, em função da preocupação com a saúde e o bem-estar (FAO, 2015).

Em relação ao impacto ambiental provocado pelo cultivo e sobre o uso de produtos químicos na produção, a pesquisa mostrou que em ambos os grupos a maioria dos pesquisados acredita que o cultivo de orgânicos provoca menos impacto ambiental e usa menos produtos químicos, média geral de 64,92\% e 69,85\%, respectivamente; contudo, de forma isolada, a porcentagem dos participantes do evento agrário - dia de campo foi superior. Mais uma vez, sugere-se que este alto valor esteja relacionado ao grau de escolaridade dos entrevistados deste grupo, que demonstrou ter mais conhecimento sobre o assunto.

A percepção sobre o uso de mão de obra no cultivo evidenciou resultados distintos entre os grupos, em que $83,33 \%$ dos entrevistados da feira do produtor afirmaram que a mão de obra é menor ou equivalente à produção convencional; por outro lado, 77,06\% dos entrevistados do evento agrário - dia de campo atestaram que o cultivo de orgânicos demanda mais mão de obra (Tabela 4), indicando um conhecimento adequado sobre o tema. Na prática, o cultivo de orgânicos demanda mais mão de obra em função do maior número de tratos culturais. Além disso, para a obtenção da certificação orgânica, Mazzoleni e Nogueira (2006) apontam a necessidade de mão de obra mais especializada, mostrando que o Equivalente Homem (EH) Total da Família, na produção de orgânicos, oscila de 1,9 EH, para os agricultores em certificação, a 1,8 EH, para os certificados.

Com relação à existência de restrições no cultivo, os resultados mostraram também diferenças de percepção, pois, no grupo de frequentadores da feira, 66,82\% acreditam que o cultivo de orgânicos apresenta restrições equivalentes ou menores que o cultivo convencional, já 73,53\% dos participantes do dia de campo relataram que o cultivo de orgânicos apresenta restrições equivalentes ou maiores que o cultivo convencional.

A Instrução Normativa (IN) n. 46, de 6 de outubro de 2011, do Ministério da Agricultura, Pecuária e Abastecimento (MAPA) (BRASIL, 2011a), que estabelece o Regulamento Técnico para os Sistemas Orgânicos de Produção Animal e Vegetal, apresenta as listas de substâncias permitidas para uso nestes sistemas, e o Plano de Manejo Orgânico contempla como fatores restritivos o histórico de utilização da área, a manutenção ou incremento da biodiversidade, o manejo dos resíduos, a conservação do solo e da água, e o manejo da produção vegetal. Destaca-se ainda, como restrição, o fato de que a conversão de áreas de agricultura convencional para o manejo orgânico é a técnica mais utilizada; por isso, o tempo básico para que esse processo se complete 
depende das circunstâncias iniciais do solo e do tipo de cultivo a ser realizado. Contudo, para culturas vegetais temporárias, o prazo varia entre um e dois anos, chegando a três anos para culturas permanentes (ORMOND et al., 2002; SCHMITH FILHO; ZULIANI, 2018).

Concernente ao consumo de água e energia na produção de orgânicos, mais de $40 \%$ dos entrevistados, em ambos os eventos, afirmaram que o consumo é similar à produção convencional. Porém, o uso de sistemas de irrigação na agricultura convencional resulta em aumento no consumo de água nesse tipo de produção. Também, a restrição do uso de agroquímicos, ao contrário da agricultura convencional, que se apoia no petróleo como matéria-prima para os agrotóxicos e fertilizantes, além da intensa utilização na mecanização, reduz o consumo de energia no cultivo dos alimentos orgânicos (CARNEIRO, s.d.). Sendo assim, constatou-se que essas informações não são percebidas e não foram apontadas pelos entrevistados neste estudo.

Segundo a Sociedade Nacional de Agricultura (CARNEIRO, s.d.), a agroecologia permite maior armazenamento de água durante a seca e maior infiltração durante as chuvas, possibilitando um maior reabastecimento dos lençóis freáticos. Relacionada a este fato, a manutenção do solo coberto reduz a evaporação, mantendo a água que já foi conservada disponível por mais tempo para as raízes da planta, situações que reduzem o consumo de água no cultivo. Mais uma vez, observa-se que os entrevistados carecem deste conhecimento.

Os resultados sobre conhecimentos gerais e importância fundamental da agricultura orgânica se mostraram bastantes discrepantes entre os quesitos avaliados e entre os grupos (Tabela 5).

Tabela 5 - Frequência de indivíduos entrevistados que responderam "sim" aos questionamentos gerais e importância da agricultura orgânica

\begin{tabular}{lcccc}
\hline & $\begin{array}{c}\text { Dia de campo } \\
\text { \% (n) }\end{array}$ & $\begin{array}{c}\text { Feira do } \\
\text { produtor } \\
\text { \% (n) }\end{array}$ & $\begin{array}{c}\text { Média } \\
\text { \% }\end{array}$ \\
\hline Conhecimentos gerais sobre agricultura orgânica & & & \\
\hline Diferença convencional, orgânico e agroecológicos & $60,00(102)$ & $72,81(83)$ & 66,40 \\
No cultivo de alimentos orgânicos, é permitido o uso de esterco & $59,41(101)$ & $54,39(62)$ & 56,90 \\
Existe relação entre produção orgânica e sustentabilidade & $95,88(163)$ & $54,39(62)$ & 75,13 \\
Produtos agroecológicos e orgânicos são sinônimos & $38,82(66)$ & $58,78(67)$ & 48,80 \\
Produto caipira é considerado orgânico & $35,29(60)$ & $52,63(60)$ & 43,96 \\
\hline Importância sobre a questão fundamental da produção orgânica & & & \\
\hline Não prejudicar a saúde & $99,41(169)$ & $68,42(78)$ & 83,92 \\
Não prejudicar o meio ambiente & $99,41(169)$ & $69,29(79)$ & 84,35 \\
Não prejudicar a saúde e o meio ambiente & $98,82(169)$ & $69,29(79)$ & 84,05 \\
\hline
\end{tabular}

Fonte: Os próprios autores.

Com relação ao questionamento sobre conhecer as diferenças entre produto convencional, agroecológico e orgânico, observou-se uma porcentagem maior de entrevistados que responderam "sim" na feira do produtor (72,81\%); contudo, em valores médios, mais da metade dos entrevistados $(66,40 \%)$ afirmou saber a diferenças. Entretanto, quando foi solicitado que explicassem a diferença (questão aberta), muitos entrevistados se abstiveram de responder (50\%) e, daqueles que responderam, a maioria (95\%) apontou como diferenças os quesitos presença ou não de agrotóxico, ser saudável e o custo. 
Em seu estudo, Pereira et al. (2015) afirmaram que quase a totalidade dos entrevistados conhecia a diferença entre os produtos, porém, a diferença observada foi atribuída somente ao fato de o produto orgânico ser livre de agrotóxicos. Já Pantaleão et al. (2015) reportaram que 91\% dos entrevistados afirmaram ser estimulados a comprar e consumir produtos orgânicos, pois tem conhecimento de que estes alimentos se associam com qualidade de vida e saúde. Assim sendo, constata-se que os resultados obtidos nesta pesquisa são similares aos citados pelos autores acima, embora seja evidente a existência de uma percepção equivocada sobre a definição de produto orgânico, já que consideram o custo, que é um fator econômico, como um dos critérios de definição do produto.

O destaque para o nível de conhecimento $(66,40 \%)$ sobre a diferença entre produtos convencionais e orgânicos pode ser associado ao considerável grau de escolaridade superior dos entrevistados: em média, 62,50\% com nível superior (Tabela 1). De igual maneira, Pereira et al. (2015) notaram também uma associação proporcional entre nível de escolaridade e saber a diferença entre os alimentos. Todavia, esses autores verificaram uma associação significativa entre renda familiar e conhecimento da diferença entre alimentos orgânicos e convencionais, mostrando que, quanto menor a renda, maior o conhecimento, situação contrária ao verificado nesta pesquisa.

Na indagação sobre ser permitido o uso de esterco animal no cultivo de alimentos orgânicos, em média, 56,90\% dos entrevistados responderam que sim. Realmente, os dejetos ou compostos orgânicos são muito utilizados como adubos na agroecologia ou produção de bases ecológicas e têm sido utilizados como fonte de nutrientes para as plantas (CHOUDHARY; BAILEY; GRANT, 1996; SCHMIDT FILHO; ZULIANI, 2018). Entretanto, ressalta-se que, para a utilização destes dejetos, eles devem passar por um processo de compostagem e bioestablilização (BRASIL, 2008). A compostagem é um processo seguro e eficaz, pois, além de eliminar micro-organismos patogênicos da matéria orgânica, possibilita obter um produto parcialmente mineralizado e de maior eficácia na nutrição de plantas em sistemas orgânicos de produção de hortaliças (SOUZA, 2003; SCHMIDT FILHO; ZULIANI, 2018).

Quanto à relação entre produção orgânica e sustentabilidade, os resultados evidenciaram uma disparidade entre os frequentadores de cada evento, sendo que a maioria $(95,88 \%)$ dos entrevistados no dia de campo afirmou que existe relação, enquanto uma parcela bem menor (54,39\%) dos entrevistados na feira apontou existir esta relação. Apesar do valor médio de 75,13\%, este dado é preocupante, pois o esperado nesta pesquisa é que os indivíduos, nos dois eventos, apresentassem uma alta percepção sobre esta relação. Carneiro (s.d.) afirmou que os produtores ecológicos têm ciência desta relação e praticam, no dia a dia, ações para minimizar os impactos e preservar os bens naturais. Portanto, ressalta-se a necessidade em divulgar o conhecimento sobre estas relações entre os consumidores.

Este estudo demonstrou que a maioria da população entrevistada no evento agrário - dia de campo acredita que produtos agroecológicos e orgânicos e produtos caipiras e orgânicos não são iguais; porém, uma grande parcela da população entrevistada na feira do produtor afirmou que estes produtos são idênticos (58,78\%), demonstrando carência de conhecimento por parte desta população (Tabela 5). Produtos agroecológicos e orgânicos e produtos caipiras e orgânicos não apresentam, necessariamente, as mesmas características. Apesar das formas de cultivo se basearem nos mesmos princípios, para que um alimento seja considerado orgânico, ele dever ser certificado. Desde 2011, todo produto orgânico deve ter selo ou ser vendido mediante a declaração de cadastro do produtor orgânico familiar. Essas medidas garantem que o produto 
comercializado esteja de acordo com as normas (BRASIL, 2011a). Schmidt Filho e Zuliani (2018) apontam que a competitividade da cadeia de orgânicos está baseada na diferenciação dos produtos e no alto valor agregado e que, para isso, é fundamental a certificação dos produtos, entre outros fatores.

Quanto à indagação sobre as questões fundamentais relacionadas à produção orgânica, se é a saúde, o meio ambiente ou a saúde e o meio ambiente, mais de $80 \%$ dos entrevistados reconheceram que todos estes pontos são importantes. Outros estudos observaram também resultados semelhantes aos desta pesquisa. Pereira et al. (2015) constataram diferentes motivações para a compra de alimentos orgânicos entre os consumidores estudados, mas que a preocupação com a saúde e com o meio ambiente se destacou. De igual maneira, em estudo anterior, realizado também em feiras na cidade de Pelotas, RS, os pesquisadores perceberam que saúde e ambiente prevaleceram como maior motivação e importância para a compra de alimentos orgânicos (ANDERSON; NASCIMENTO; LOVATTO, 2009).

De fato, a agricultura orgânica é uma atividade de produção agropecuária que gera alimentos com boa qualidade nutricional, livres de resíduos de agroquímicos que podem prejudicar a saúde humana ou o meio ambiente (SCHMIDT FILHO; ZULIANI, 2018).

Apesar do valor médio considerável, os valores isolados refletem, novamente, que os frequentadores do evento agrário - dia de campo apresentam um melhor entendimento comparados aos frequentadores da feira (98,82\% vs. 69,29\%), sobre os benefícios à saúde dos consumidores e ao meio ambiente.

Os resultados gerais deste estudo, com relação aos quesitos que devem ser considerados no sistema de produção de orgânicos, comparativo entre produto e cultivo convencional e de orgânicos, como também sobre os conhecimentos gerais acerca de agricultura orgânica, revelaram diferenças entre os grupos estudados, evidenciando lacunas do conhecimento ou noções equivocadas, principalmente entre os frequentadores da feira do produtor. Como já mencionado neste trabalho anteriormente, credita-se que parte destes resultados seja atribuída ao menor nível de escolaridade dos frequentadores desta feira. Portanto verifica-se a necessidade de ações de divulgação sobre as formas de cultivo e diferenças entre os produtos agroecológicos, orgânicos e convencionais, a fim de complementar e ajustar o conhecimento da comunidade sobre estes assuntos. Como base para promoção deste processo, deve-se considerar os preceitos tanto da educação ambiental quanto da ecológica e agroecológica.

No tocante à Educação Ambiental, a Lei n. 9.795, criada em 27 de abril de 1999, dispõe sobre a Educação Ambiental, instituiu a Política Nacional de Educação Ambiental (PNEA) e aponta que a educação ambiental envolve valores, teorias e práticas que almejam a manutenção da vida e a construção de um mundo melhor, buscando o enfrentamento da degradação socioambiental por meios dialógicos e participativos (BRASIL, 1999).

A PNEA apontou que a educação ambiental é um processo no qual o indivíduo e a coletividade constroem valores sociais, conhecimentos, habilidades, atitudes e competências voltadas para a conservação do meio ambiente, essencial para uma vida saudável e sustentável, e que deve estar presente, de forma articulada, em todos os níveis e modalidades do processo educativo, em caráter formal e não formal (BRASIL, 1999). A Lei n. 9.795 afirma também que todos têm direito à educação ambiental, incumbindo vários setores e segmentos da sociedade para o alcance de suas ações, entre elas, as instituições educativas, que devem promover a educação ambiental de maneira integrada aos programas educacionais que desenvolvem (BRASIL, 1999). 
Os objetivos fundamentais da educação ambiental, elencados pela Lei n. 9.795, incluem o desenvolvimento de uma compreensão integrada do meio ambiente em suas múltiplas e complexas relações, envolvendo aspectos ecológicos, psicológicos, legais, políticos, sociais, econômicos, científicos, culturais e éticos; a garantia de democratização das informações ambientais e o estímulo e o fortalecimento de uma consciência crítica sobre a problemática ambiental e social (BRASIL, 1999).

Sendo assim, a PNEA envolve órgãos e entidades integrantes do Sistema Nacional de Meio Ambiente (SISNAMA), instituições educacionais públicas e privadas, órgãos públicos da União, dos estados, do Distrito Federal e dos municípios, além de organizações não governamentais com atuação em educação ambiental. Salienta também que as atividades devem ser desenvolvidas na educação em geral e na educação escolar, com atuações inter-relacionadas.

Entre as ações de estudos, pesquisas e experimentações listadas na PNEA, está o desenvolvimento de instrumentos e metodologias, visando à incorporação da dimensão ambiental, de forma interdisciplinar, nos diferentes níveis e modalidades de ensino; a busca de alternativas curriculares e metodológicas de capacitação na área ambiental; e o apoio a iniciativas e experiências locais e regionais, incluindo a produção de material educativo.

Esta lei propõe também ações de Educação Ambiental no Ensino Formal, sendo desenvolvidas no âmbito dos currículos das instituições de ensino públicas e privadas, englobando todas as esferas da educação básica, e que a educação ambiental será desenvolvida como uma prática educativa integrada, contínua e permanente em todos os níveis e modalidades do ensino formal; contudo, não há a necessidade de sua implantação como disciplina específica no currículo de ensino. Quanto à Educação Ambiental Não Formal, a PNEA reporta que esta modalidade constitui ações e práticas educativas voltadas à sensibilização da coletividade sobre as questões ambientais e à sua organização e participação na defesa da qualidade do meio ambiente (BRASIL, 1999).

Além da necessária consolidação das propostas de Educação Ambiental postuladas na PNEA, este estudo salienta a importância das ações de educação e alfabetização ecológica e agroecológica como base para promoção deste processo, visto que, assim como a educação ambiental e ecológica, a agroecologia busca a ressignificação na relação entre as pessoas e delas com o meio ambiente, bem como objetivam os cuidados com a terra, a biodiversidade, a produção de alimentos saudáveis e a promoção de modos de vida mais sustentáveis no campo e na cidade (SORRENTINO et al., 2015), mesmo que estas características resultem em menor tamanho e pior aparência do produto cultivado.

Altieri (2004) enfatiza que, diante da importância da agroecologia, para a formação do cidadão do século XXI, é preciso, inclusive, incorporar no currículo educacional temas e métodos agroecológicos, ou seja, promover a alfabetização agroecológica, buscando divulgar as diferentes formas de produção de alimentos. Capra (2013) afirma que a alfabetização agroecológica é baseada em três eixos filosóficos: a natureza como mestra, que considera a crença da interação com os sistemas naturais; a cultura da infância; e o ser integral. Estes eixos buscam proporcionar múltiplas experiências por meio do exercício de diferentes linguagens, mostrando que o ser humano é feito de múltiplas dimensões, as quais precisam ser igualmente nutridas.

Em suma, diante dos resultados encontrados, é pertinente promover práticas de educação ambiental, ecológica e de alfabetização agroecológica, e, ao contrário de Capra (2013), que preconiza a alfabetização agroecológica principalmente com crianças, esse estudo propõe ações de andragogia, ou seja, que envolvam a disseminação do conhecimento para indivíduos 
adultos. A andragogia é uma metodologia para educação de adultos, de diferentes idades e níveis socioculturais (NOGUEIRA, 2004).

Portanto, pondera-se que, para que os objetivos da educação ambiental e ecológica e a alfabetização agroecológica se concretizem, é importante investir em educação, em diferentes idades e níveis, divulgar conceitos e práticas, objetivando criar cidadãos que saibam pensar em relações, conexões e contextos entre alimentos, saúde e meio ambiente.

Neste panorama, as ações propostas são: discutir e propor a inclusão destas tratativas e vivências na base curricular, do ensino fundamental ao superior, em instituições públicas, privadas e, inclusive, em organizações do terceiro setor que contemplem a capacitação de indivíduos e a inclusão na sociedade e no mercado de trabalho; confeccionar e distribuir cartilhas que contemplem o assunto em vários locais do município, como a própria feira do produtor, a feira livre, a feira de produtos orgânicos, entre outros locais que forem pertinentes a sua distribuição; sugerir a inclusão, em eventos ocorrentes no município, promovidos pelo poder público ou por entidades privadas, de palestras que abordem este tema; e, por fim, inserir discussões e palestras sobre os temas no evento Dia de Campo da UNICESUMAR. A divulgação destes conceitos, além de agregar conhecimento aos indivíduos, permitirá um critério fiável e melhor consciência no momento da escolha e compra dos alimentos.

\section{CONCLUSÕES}

Este estudo mostrou que a maioria dos pesquisados é jovem ou adulto jovem, residente na zona urbana e que apresenta renda familiar mensal entre 3 e 8 salários. Observaram-se diferenças quanto ao sexo e grau de escolaridade entre os grupos, sendo que, na feira do produtor, a maioria era do sexo feminino e com menor grau de escolaridade.

Apesar de os resultados médios serem satisfatórios em todos os quesitos avaliados, verificaram-se diferenças entre os grupos estudados, evidenciando lacunas do conhecimento ou percepções equivocadas no grupo de frequentadores da feira do produtor. Parte destes resultados é atribuída ao menor nível de escolaridade destes entrevistados.

Os resultados evidenciaram a necessidade de ações de divulgação sobre as formas de cultivo e diferenças entre os produtos agroecológicos, orgânicos e convencionais. Por isso, a fim de complementar e ajustar o conhecimento da comunidade sobre estes temas, conclui-se que é imperativo que ações que fomentem a educação ambiental, ecológica e a alfabetização agroecológica sejam estimuladas, a fim de divulgar as características de um produto orgânico, suas formas de cultivo, suas restrições de cultivo, e seus benefícios ambientais e à saúde dos seus consumidores.

\section{REFERÊNCIAS}

AAKER, D. A.; KUMAR, V.; LEONE, R. P.; DAY, G. S. Marketing Research. 12. ed., New York: John Wiley \& Sons, Inc, 2015. 760 p.

ALMEIDA, T. D.; MOREAU, A. M. S. S.; MOREAU, M. S.; PIRES, M. D. M.; FONTES, E. D. O.; GÓES, L. M. Reorganização socioeconômica no extremo sul da Bahia decorrente da introdução da cultura do eucalipto. Revista Sociedade \& Natureza, Uberlândia, v. 20, n. 2, p. 5-18, 2008. Disponível em: http://www.scielo. br/pdf/sn/v20n2/a01v20n2.pdf. Acesso em: 12 jun. 2018.

ALTIERI, M. Agroecologia: a dinâmica produtiva da agricultura sustentável. 4. ed. Porto Alegre: Editora da UFRGS, 2004. 
ANDERSON, F. S.; NASCIMENTO, S. G.; LOVATTO, P. B. Estudo do perfil dos consumidores em duas feiras livre de base ecológica do município de Pelotas, RS, Brasil. In: ENCONTRO DE PÓS-GRADUAÇÃO, 11.; MOSTRA CIENTÍFICA, 1., 20 a 23 de outubro, 2009, Pelotas. Anais [...]. Pelotas: UFPEL, 2009. Disponível em: http://www.ufpel.edu.br/. Acesso em: 12 jun. 2018.

ANDREAZZI, M. A.; GASPAROTTO, F.; PACCOLA, E. A. S.; RODRIGUES, A. F. C.; SILVA, C. N.; LIZAMA, M. L. A. P. Giant african snail, Achatina fulica Bowdich, 1822: an environmental and public health problem. Acta scientiarum. Biological Sciences, Maringá, v. 39, n. 3, p. 301-07, 2017.

BRASIL. Ministério do Desenvolvimento Agrário. Plano Nacional de Agroecologia e Produção Orgânica [PLANAPO] 2016-2019. Brasília-DF: MDA, 2016. Disponível em: http://www.agroecologia.org.br/ files/2016/06/Planapo-2016-2019.pdf. Acesso em: 15 abr. 2018.

BRASIL. Ministério da Educação. Lei Federal n. 13.186, de 11 de novembro de 2015. Dispõe sobre a Política de Educação para o Consumo Sustentável. Brasília-DF: MEC, 2015. Disponível em: http://www.planalto. gov.br/ccivil_03/_Ato2015-2018/2015/Lei/L13186.htm . Acesso em: 8 jun. 2018.

BRASIL. Ministério do Desenvolvimento Agrário. Plano Nacional de Agroecologia e Produção Orgânica PLANAPO - 2013-2015. Brasília-DF: MDA, 2013. Disponível em: http://www.mda.gov.br/sitemda/sites/ sitemda/files/user_img_19/BrasilAgroecologico_Baixar.pdf. Acesso em: 15 jul. 2018.

BRASIL. Ministério de Estado da Agricultura, Pecuária e Abastecimento. Instrução Normativa n. 46, de 6 de outubro de 2011. Regulamento Técnico para os Sistemas Orgânicos de Produção Animal e Vegetal. Brasília-DF: Mapa, 2011a. Disponível em: http://www.aao.org.br/aao/pdfs/legislacao-dos-organicos/ instrucao-normativa-n46.pdf. Acesso em: 10 abr. 2018.

BRASIL. Ministério do Meio Ambiente. Plano de Ação para Produção e Consumo Sustentáveis (PPCS). Brasília-DF: MMA, 2011b. Disponível em: http://www.mma.gov.br/responsabilidade-socioambiental/ producao-e-consumo-sustentavel/plano-nacional. Acesso em: 8 jun. 2018.

BRASIL. Ministério de Estado da Agricultura, Pecuária e Abastecimento. Instrução Normativa n. 64, de 18 de dezembro de 2008. Regulamento técnico para os sistemas orgânicos de produção animal e vegetal. Brasília-DF: MDA, 2008. p. 30.

BRASIL. Lei n. 9. 795, de 27 de abril de 1999. Dispõe sobre a educação ambiental, institui a Política Nacional de Educação Ambiental e dá outras providências. Brasília-DF, 1999 Disponível em: http://www.mma.gov. br/port/conama/legiabre.cfm?codlegi=321. Acesso em: 8 jun. 2018.

BRITO, P. F.; MELLO, M. G. S. Horta agroecológica como caminho para encontros. Caderno Saúde Pública, Rio de janeiro, v. 32, n. 11, 2016.

BRITO, M. M. A. Introdução à amostragem. In: ABDAL, A.; OLIVEIRA, M. C. V.; GHEZZI, D. R.; SANTOS JUNIOR, J. Métodos de pesquisa em Ciências Sociais - bloco quantitativo. São Paulo: CEBRAP, 2016.

CAPRA, F. Alfabetização ecológica: a educação das crianças para um mundo sustentável. São Paulo: Cultrix, 2013. 312 p.

CARNEIRO, G. R. Dez bons motivos para o consumo de alimentos orgânicos agroecológicos. Portal eletrônico Ambiente Brasil, [s.d.]. Disponível em: http://ambientes.ambientebrasil.com.br/agropecuario/ artigo_agropecuario/dez_bons_motivos_para_o_consumo_de_alimentos_organicos_agroecologicos. html. Acesso em: 20 jul. 2018.

CHOUDHARY, L. D.; BAILEY, L. D.; GRANT, C. A. Review of the use of swine manure in crop production: effects on yield and composition and on soil and water quality. Waste Management e Research, v. 14, p. 581-95, 1996. 
CRONBACH, L. J. Coefficient Alpha and the internal structure of tests. Psychometrika, Boston, v. 16, n. 3, p. 297-334, 1951.

FOOD AND AGRICULTURE ORGANIZATION OF THE UNITED NATIONS [FAO]. OCDE-FAO: perspectivas agrícolas 2015-2024. [Relatório]. Paris: FAO, 2015. Disponível em: www.fao.org/3/b-i4761o.pdf. Acesso em: 10 jul. 2018.

FEITOSA, M. Política Nacional de Produção e Consumo Sustentáveis. Safra - Revista do Agronegócio, Goiânia, 16 jun. 2016. Disponível em: http://revistasafra.com.br/politica-nacional-de-producao-econsumo-sustentaveis/. Acesso em: 8 jul. 2018.

FONSECA, M. H.; BITTENCOURT, J. V. M.; PICININ, C. T. Perfil dos agricultores familiares produtores de orgânicos da cidade de Ponta Grossa. In: CONGRESSO BRASILEIRO DE ENGENHARIA DE PRODUÇÃO, 7., 6 a 8 dez. 2017, Ponta Grossa. Anais [...]. Ponta Grossa: UTFPR, 2017.

HORA, H. R. M.; MONTEIRO, G. T. R.; ARICA, J. Confiabilidade em questionários para qualidade: um estudo com o Coeficiente Alfa de Cronbach. Produto \& Produção, Porto Alegre, v. 11, n. 2, p. 85-103, 2010.

HUNDLEY, G. M. C.; NAVARRO, R. D.; FIGUEIREDO, C. M. G.; NAVARRO, F. K. S. P.; PEREIRA, M. M.; RIBEIRO FILHO, O. P.; SEIXAS FILHO, J. T. Aproveitamento do efluente da produção de tilápia do Nilo para o crescimento de manjericão (Origanum basilicum) e manjerona (Origanum majorana) em sistemas de aquaponia. Revista Brasileira de Agropecuária Sustentável, Viçosa, MG, v. 3, n. 1, p. 51-5, 2013.

JACOB, L. B. Agroecologia na universidade: entre vozes e silenciamentos. Cidade: Ed. Appris, 2016.

LEME, L. M. L.; LUCAS, A.; SORRENTINO, M. Limites e potencialidades de um núcleo de agroecologia no ambiente educacional de um campus de ciências agrárias. Revista Eletrônica do Mestrado em Educação Ambiental, Rio Grande, v. 1, n. 1, p. 243-60, 2017.

LIMA FILHO, D. O. Percepção do consumidor sobre produtos orgânicos. Revista Brasileira de Marketing, v. 11, n. 1, p. 29-46, 2012.

LOESCHI, C.; HOELTGEBAUM, M. Métodos Estatísticos Multivariados. São Paulo: Saraiva, 2012.

MATTHIENSEN, A. Uso do Coeficiente Alfa de Cronbach em Avaliações por Questionários. Boa Vista: Embrapa, 2011.

MAZZOLENI, E. M.; NOGUEIRA, J. M. Agricultura orgânica: características básicas do seu produtor. Revista e Economia e Sociologia Rural, Brasília, v. 44, n. 2, p. 263-93, 2006.

MORAES, M. L.; GUILHERME, D. O.; FERNANDES, F. M. B.; CASAGRANDE, V. M. G.; MELO, A. M. S. V.; DE PAIVA, A. S.; CEREDA, M. P. Análise do perfil dos consumidores de produtos orgânicos de Campo Grande, Mato Grosso do Sul. Cadernos de Agroecologia, Rio de Janeiro, v. 9, n. 4, 2015.

NASCIMENTO, T. C.; MENDONÇA, A. T. B.; CUNHA, S. K. Inovação e sustentabilidade na produção de energia: o caso do sistema setorial de energia eólica no Brasil. Cadernos EBAPE.BR, v. 10, n. 3, p. 630-51, 2012.

NOGUEIRA, M. A. Andragogia: que contributos para a prática educativa? Revista Linhas, Florianópolis, v. 5, n. 2, p. 1-23, 2004.

ORGANIZAÇÃO DAS NAÇÕES UNIDAS PARA A EDUCAÇÃO A CIÊNCIA E A CULTURA [UNESCO]. Agenda de desenvolvimento pós-2015: UNESCO e os objetivos de desenvolvimento sustentável. Brasília-DF: UNESCO, 2015. Disponível em http://www.unesco.org/new/pt/brasilia/post-2015-development-agenda/. Acesso em: 8 mar. 2018. 
ORMOND, J. G. P.; DE PAULA, S. R. L.; FAVERET FILHO, P.; ROCHA, L. T. M. Agricultura orgânica: quando o passado é futuro. Rio de Janeiro: BNDES, 2002. Disponível em: https://web.bndes.gov.br/ bib/jspui/bitstream/1408/2479/1/BS\%2015\%20Agricultura\%20org\%C3\%A2ncia_P.pdf. Acesso em: 28 maio 2018.

PANTALEÃO, E. O.; BRESSAN, I.; PIRES, W. L. R.; OKAWADA, F. C. F.; FERRER SILVA, I. A. Perfil do consumidor de produtos agroecológicos comercializado na Ecofeira em Cuiabá-MT. In: BRAZILIAN CONGRESS OF AGROECOLOGY, 9., 28 set. a 1o out., 2015, Belém, PA. Anais [...]. Belém: ABA, 2015.

PEREIRA, M. C.; MÜLLER, C. R.; RODRIGUES, F. S. A., MOUTINHO, A. B. A.; RODRIGUES, K. L.; BOTELHO, F. T. Mudança no perfil sociodemográfico de consumidores de produtos orgânicos. Ciência \& Saúde Coletiva, Rio de janeiro, v. 20, n. 9, p. 2797-804, 2015.

PIMENTA, V. P.; SENA, J. O. A.; MOURA, L. P. P.; CUNHA, F. A. D.; RUPP, L. M.; HISANO, L. K.; CALDAS, R. G.; FREITAS, I. D.; VIEIRA, D. T. Percepção dos consumidores quanto aos produtos orgânicos na região de Maringá-Paraná, Brasil. Universidade Estadual de Maringá. Revista Brasileira de Agroecologia, Rio de Janeiro, v. 4, n. 2, p. 2903-7, 2009.

PRODANOV, C. C.; FREITAS; E. C. Metodologia do trabalho científico: métodos e técnicas da pesquisa e do trabalho acadêmico. 2. ed. Novo Hamburgo: Feevale, 2013.

REICHENHEIM, M. E.; MORAES, C. L. Operationalizing the cross-cultural adaptation of epidemological measurement instruments. Revista Saúde Pública, São Paulo, v. 41, n. 4, p. 665-73, 2007.

SANTOS, R. S. Alimentos convencionais, orgânicos, hidropônicos e transgênicos, qual a diferença? Portal AgroDebate, Brasília, 2013. Disponível em http://www.diadecampo.com.br/zpublisher/materias/Materia. asp?id=29427\&secao=ArtigAr\%20Especiais. Acesso em: 12 mar. 2018.

STATISTICAL ANALYSIS SYSTEM [SAS]. Institute Inc. 2002-2003. Release 9.3. (Software). Cary, USA: SAS, 2003. SCHMIDT FILHO, E.; ZULIANI, D. B. Cadeias produtivas do café e de produtos orgânicos. Maringá: Unicesumar, 2018. 195 p.

SORRENTINO, M.; MORAES, F. C.; SILVA, L. F.; RAYMUNDO, M. H. A.; PORTUGAL, S.; CAPELLO, A. P. Alfabetização Agroecológica Ambientalista: interpretando e transformando o socioambiente local e global. In: BRIANEZI, T.; RAYMUNDO, M.; SORRETINO, M. Como construir políticas públicas de educação ambiental para sociedades sustentáveis? São Carlos, SP: Diagrama Editorial, 2015. p. 172-91.

SOUZA, J. L. Manual de horticultura orgânica. Viçosa: Aprenda Fácil, 2003. 560 p.

URPIA, A. G. B. C.; MASSUDA, E. M.; MACHADO, C. P. Uma análise da percepção de gestores sobre a presença de características intraempreendedoras em instituição de ensino. In: PICANÇO, F. C. A.; PERIOTTO, T. R. C. (Org.). Empreendedorismo \& Inovação 658. Maringá: Cesumar, 2017. 342 p.

VACCARI, L. C.; COHEN, M.; ROCHA, A. M. C. O hiato entre atitude e comportamento ecologicamente conscientes: um estudo com consumidores de diferentes gerações para produtos orgânicos. Revista Eletrônica de Gestão Organizacional, Recife, v. 14, esp. p. 44-58, 2016.

VERONA, L. A. F; DIZ, O.M.; HEMP, S.; NESI, C. O perfil dos consumidores de produtos orgânicos da feira da cidade de Chapecó-SC. Revista Brasileira de Agroecologia, Dois Vizinhos, v. 4, n. 2, 2009.

WILLER, H.; KILCHER, L. The world of organic agriculture - statistics and emerging trends. Bonn: Federação Internacional dos Movimentos de Agricultura Orgânica (IFOAM), 2010. Disponível em: http://www.ifoam. org/pdfs/World_of_OA_Teaser.pdf. Acesso em: 20 maio 2018. 
ZULAUF, W. E. O meio ambiente e o futuro. Estudos avançados, São Paulo, v. 14, n. 39, p. 85-100, 2000.

\section{Sobre os autores:}

Natália Christina da Silva Matos: Mestre em Tecnologias Limpas pelo Centro Universitário de Maringá (UNICESUMAR). Tecnóloga em Agronegócio. Assistente de cursos EAD no Centro Universitário Cidade Verde (UniFCV). E-mail: nataliacsmatos@gmail.com, Orcid: http://orcid.org/0000-0002-4068-9602

Márcia Aparecida Andreazzi: Pós-doutora pela Universidade Federal de Minas Gerais (UFMG). Doutora em Produção Animal pela Universidade Estadual de Maringá (UEM). Mestre em Biologia Celular pela UEM. Zootecnista. Coordenadora e docente do Programa de Pós-Graduação em Tecnologias Limpas do Centro de Ensino Superior de Maringá (UNICESUMAR). Docente do Curso de Medicina Veterinária do UNICESUMAR. E-mail: marcia.andreazzi@unicesumar.edu.br, Orcid: http://orcid.org/0000-0002-8379-2693

Maria de Los Angeles Perez Lizama: Doutora e mestre em Ecologia pela Universidade Estadual de Maringá (UEM). Bióloga. Docente do curso de Medicina Veterinária e do Programa de Mestrado em Tecnologias Limpas do Centro Universitário de Maringá (UNICESUMAR). Pesquisadora ICETI/UNICESUMAR. E-mail: maria.lizama@unicesumar.edu.br, Orcid: http://orcid.org/0000-0002-9714-9383

Arthur Gualberto Bacelar da Cruz Urpia: Doutor e mestre em Economia pela Universidade Federal do Rio de Janeiro (UFRJ). Docente do curso de Administração e de Economia, e do Mestrado em Gestão do Conhecimento no Centro Universitário de Maringá (UNICESUMAR). Economista. Pesquisador ICETI/UNICESUMAR. E-mail: arthur.urpia@unicesumar.edu.br, Orcid: http://orcid.org/0000-0002-5273-6373 